\title{
2D: 4D, Lateralization and Strength in Handball Players
}

\author{
Nebahat Eler ${ }^{1}$, Serdar Eler ${ }^{2}$ \\ ${ }^{1}$ Physical Education and Sports, Bulent Ecevit University, Zonguldak, Turkey. \\ ${ }^{2}$ Faculty of Sports Sciences, Gazi University, Ankara, Turkey \\ Correspondence: Nebahat Eler, Physical Education and Sports, Bulent Ecevit University, Zonguldak, Turkey.
}

Received:March 11, 2018

doi:10.11114/jets.v6i5.3220

\author{
Accepted: April 12, 2018 \\ Online Published: April 18, 2018 \\ URL: https://doi.org/10.11114/jets.v6i5.3220
}

\begin{abstract}
Lateralization, which is also known as hand preference, and 2D:4D finger ratio is a sign of prenatal testosterone and known to be associated with strength. The aim of this study is to investigate the relationship between $2 \mathrm{D}$ : $4 \mathrm{D}$, lateralization and hand grip strength in relation to hand and forearm that are thought to be effective in handball in elite handball players. 67 female and 67 male elite players participated in this study. The height, weight, body-mass index and hand preference of these athletes have been identified and 2D: 4D finger measurements and hand grip strength tests were performed. When identifying the preferences regarding lateralization, the hand distribution preference was determined by the Oldfield questionnaire and evaluated using the Geschwind score. After photocopy images of the two hands of the athletes were taken, their finger lengths were measured Hand grip strength was determined by a Jamar hydraulic dynamometer. Strong correlation was found especially between 2D: 4D and dominant hand grip strength in male and female elite handball players. The ratio of left-handedness due to the positions of players during the game among male and female athletes has been found to be higher than that of the general population. With regard to gender, 2D: 4D was found to be lower in males than females but hand grip was found to be higher in males than females. Besides, a significant correlation between height and BMI with 2D:4D, sport age, height, body weight and hand grip strength was found. This study emphasizes the importance of 2D: 4D, handgrip strength and hand preference in handball.
\end{abstract}

Keywords: 2D:4D, lateralization, handgrip strength, handball

\section{Introduction}

Cerebral lateralization is described as the anatomic and functional differentiation between the right and left hemispheres of the brain (Tan, 1985). Gender difference was reported to be effective in lateralization (Powel et.al., 2012). Apart from the influence of gender hormones on lateralization, the formation of the ratio of the second and fourth finger length (2D:4D) was proven to be associated with fetal testosterone (Manning and Taylor, 2001). Manning et al. (1998) asserted that the difference in 2D:4D between the genders is due to the exposure to fetal prenatal testosterone. It is suggested that prenatal testosterone has a negative correlation with 2D:4D; on the other hand, prenatal estrogen has a positive correlation with 2D:4D (Manning et al., 1998). This relationship is negatively correlated with sportive performance Hönekopp and Schuster , 2010). The average of 2D:4D in males is lower than that of females (Manning et al., 1998; Van Honka et al., 2011; Hönekopp and Watson , 2011; Phelps, 1952). Therefore, it could be rational to assume that the negative correlation between 2D:4D and physical strength affects 2D:4D and sports performance (Hönekopp et al., 2006; Malas et al., 2006).

When Manning and Taylor (2001), compared the 2D:4D ratios of professional players with the control group, they found that it is significantly lower. Besides, they also suggest that international players have lower 2D:4D ratios when compared to other athletes.

Moreover, a significant negative correlation in terms of performance between 2D:4D and such sports as rugby (Bennett et al., 2010), fencing (Voracek et al., 2006), skiing and football (Manning and Taylor, 2001) was found (Hönekopp et al., 2006; Manning, 2002).

It was pointed out that the average 2D:4D ratio does not change in pregnancy (Galis etal., 2010) and even in adulthood Çelik et al., 2010). In addition to being a predictor of sportive performance features, 2D:4D ratio may pave the way for the scientists who quest for discovering talent at an early age. Sportive performance depends not only on a well-developed cardio vascular system but also muscle strength. There is a more direct relationship between 2D:4D and muscle strength (Tamiya et al., 2012). There are studies suggesting that 2D:4D ratio affects muscle and hand grip strength (Fink et al., 
2006; Moffit and Swanik, 2010). Gripping strength is important in catching and throwing the ball or other equipment in different sports and it is a physiologic variable affected by a number of factors such as age, gender and body size. There are strong correlations between gripping strength and different anthropometric features like weight, height, hand length etc. (Sing et al., 2009; Koley et al., 2009; Jürime et al., 2008; Kaur, 2009). In handball, both gripping strength and hand anthropometry are important. All the shoots and catches are related to the wrist and fingers. When fingers and the parameters of hand surface are longer and the fingers are stronger, gripping strength could be better and this could affect the performance positively (Visnapuu and Jurımae, 2007).bDetermining hand preference when finding out the gripping strength is more appropriate to decide cerebral laterality (Curt et al., 1992). Lateralization determining is used to identify the brain spot where hand preference is dominant and is asserted to be the most practical method (Bryden, 1975). Lateralization is correlated with high performance in some sports branches in which require high competition such as handball, fencing, ice hockey, baseball and tennis (Harris, 2010; Puterman et al., 2010; Loffing et al., 2010). Depending on the sports and position in the game, hand preference may provide advantage or disadvantage in the competition in some sports branches (Abel and Kruger, 2004). In some fast and quick sports such as handball, tennis and fencing where making quick decisions is important, the players who use their left hands while playing are advantageous (Lawler and Lawler, 2011) because the habit of left-handed players' predicting the move of their opponents is higher than right-handed players (Loffing et al., 2012b). Therefore, it is important to study hand preference, 2D:4D and hand grip strength together. There are some studies carried out on the relationship between 2D:4D and gripping strength in sports branches such as fencing, baseball and swimming. However, to the best of our knowledge, the literature on gripping strength with 2D:4D and lateralization in elite handball players is very limited (Baker et al., 2013; Kaplan, 2016). The aim of this study is to investigate the correlation with hand preference, $2 \mathrm{D}: 4 \mathrm{D}$ and hand grip strength in elite male and female handball players.

\section{Method}

\subsection{Participants}

67 male and 67 female, that is, a total of 134 elite handball players who play in 2017-2018 Turkish Super League participated in this study. The athletes who participated in this study were selected from those who played and played in Turkish national team before. 2016-2017 Turkey are also athletes who played in the first 6 teams in the Super League ranking.

\subsection{Measures}

The height, weight, body mass index (BMI), finger measurements for 2D:4D and hand grip strength tests of these athletes were carried out. For these measurements a Holtain anthropometric set was used. The weights of the athletes were determined using a digital bascule with a $0.1 \mathrm{~kg}$ of sensitivity and their heights were measured with a stadiometer with a $0.01 \mathrm{~m}$ of sensitivity and the BMI was calculated using the body mass $(\mathrm{kg}) /$ height $\left(\mathrm{m}^{2}\right)$ formula (Table 1$)$.

Table 1. Some demographic features of the athletes

\begin{tabular}{|c|c|c|c|c|c|c|c|c|c|c|c|c|c|c|c|c|}
\hline & \multicolumn{8}{|l|}{ Male } & \multicolumn{8}{|c|}{ Female } \\
\hline & \multicolumn{4}{|c|}{ Right-handed (n-54) } & \multicolumn{4}{|c|}{ Left-handed (n-13) } & \multicolumn{4}{|c|}{ Right-handed (n-56) } & \multicolumn{4}{|c|}{ Left-handed (n-11) } \\
\hline & Ave. & $\mathrm{SD}$ & Min & Max & Ave. & $\mathrm{SD}$ & Min & Max & Ave. & $\mathrm{SD}$ & Min & Max & Ave. & $\mathrm{SD}$ & Min & $\operatorname{Max}$ \\
\hline $\mathrm{Ag}$ & 25,24 & 4,27 & 18 & 36 & 22,69 & 3,3 & 18 & 28 & 25,94 & 4,9 & 18 & 37 & 25,1 & 4,38 & 19 & 32 \\
\hline Spor & 31 & 4,07 & 5 & 25 & 10,92 & 3,3 & 7 & 18 & 14,41 & 4,88 & 7 & 26 & 13,55 & 4,78 & 7 & 22 \\
\hline Height $(\mathrm{cm})$ & 188,3 & 5,17 & 176 & 198 & 187 & 6,31 & 176 & 198 & 177 & 5,02 & 169 & 189 & 178,2 & 4,96 & 172 & 186 \\
\hline Weight $(\mathrm{kg})$ & 89,78 & 6,58 & 75 & 110 & 87,77 & 6,93 & 79 & 104 & 69,45 & 6,12 & 60 & 85 & 70,5 & 6,41 & 63 & 84 \\
\hline $\mathrm{BMI}\left(\mathrm{kg} / \mathrm{m}^{2}\right)$ & 25,22 & 1,17 & 23,05 & 28,05 & 25,06 & 0,86 & 23,9 & 26,5 & 22,09 & 1,02 & 20,19 & 24,54 & 22,17 & 1,19 & 20,37 & 24,28 \\
\hline
\end{tabular}

When identifying the preferences regarding lateralization, the hand distribution preference was determined by the Oldfield questionnaire and evaluated using the Geschwind score. When grouping, the ones who are right-handed and full right-handed were considered as "right-handed" and the ones who are left-handed and full left-handed were considered as "left-handed". After the athletes' photocopy images of their both hands were taken, their finger lengths were measured using a vermian caliper that can measure up to $0.05 \mathrm{~mm}$ between the basal line at the proximal part of the 2nd finger (index finger) and the 4th finger (ring finger) on the palm of the hand. The measurements were carried out by the same person twice to ensure reliability and they were noted down in millimeters $(\mathrm{mm})$. In order to determine the ratio, the length of the second finger was divided into the length of the fourth finger. The values of hand grip strength were measured with a hand dynamometer which is consistent with international standards. First the dominant side was measured using a Jamar hydraulic (Sammons Preston, USA). The measurements were taken while the athlete was sitting and the forearm is at $90 \mathrm{o}$ flexion without support from the torso. The right and the left hand were measured twice separately and the best value was recorded as $\mathrm{kg}$ (Table 2). 
Table 2. Hand preference of the athletes, 2D:4D and values of gripping strength values

\begin{tabular}{|c|c|c|c|c|}
\hline \multirow[b]{4}{*}{ Hand preference } & \multicolumn{2}{|l|}{ Male } & \multicolumn{2}{|l|}{ Female } \\
\hline & Right-handed (n-54) & Left-handed (n-13) & Right-handed (n-56) & Left-handed (n-11) \\
\hline & Ave. SD Min Max & Ave. SD Min Max & Ave. SD Min Max & Ave. SD Min Max \\
\hline & $\begin{array}{llll}0,67 & 0,26 & 0,2 & 1 \\
\end{array}$ & 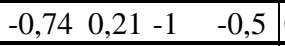 & $\begin{array}{llll}0,78 & 0,19 & 0,2 & 1 \\
\end{array}$ & $\begin{array}{llll}-0,72 & 0,27 & -1 & -0,1 \\
\end{array}$ \\
\hline Right hand 2D:4D & $\begin{array}{lllll}0,93 & 0,01 & 0,89 & 0,95\end{array}$ & $\begin{array}{lllll}0.97 & 0,01 & 0.94 & 1.01 \\
\end{array}$ & $0,95 \quad 0,020,91 \quad 0,99$ & $\begin{array}{llll}0,98 & 0,01 & 0,94 & 1 \\
\end{array}$ \\
\hline Left hand 2D:4D & $\begin{array}{llll}0,96 & 0,02 & 0,93 & 0,99 \\
\end{array}$ & $0,93 \quad 0,02 \quad 0,9 \quad 1$ & $\begin{array}{llllll}0,98 & 0,02 & 0,94 & 1,02\end{array}$ & $\begin{array}{llll}0,95 & 0,01 & 0,91 & 0,96 \\
\end{array}$ \\
\hline DHGS & $53,965,1742 \quad 61$ & $51,085,2 \quad 41 \quad 61$ & $40,864,9434 \quad 51$ & $40,45 \quad 4,5131 \quad 51$ \\
\hline NDHGS & $\begin{array}{llll}49,7 & 4,92 & 38 & 57 \\
\end{array}$ & $47,925,3139 \quad 58$ & $37,31 \quad 4,76 \quad 29 \quad 47$ & $\begin{array}{llll}36,35 & 4,2 & 30 & 48 \\
\end{array}$ \\
\hline
\end{tabular}

DHGS: dominant hand grip strength- NDHGS: non-dominant hand grip strength

\subsection{Statistical Analysis}

The obtained data were evaluated using SPSS 16 software. In the statistical analysis, $\mathrm{t}$ test and correlation analysis were used in the dependent and independent groups.

\section{Results}

While $\% 75.93$ of the male athletes is right-handed, $\% 24.07$ of them is left-handed. On the other hand, it was found that $\%$ 80.36 of the female athletes is right-handed, whereas \% 19.64 of them is left-handed (Table 3.).

Table 3. Hand distribution preference of the athletes

\begin{tabular}{|c|c|c|c|c|}
\hline & & \multicolumn{2}{|c|}{ Hand preference } & \multirow{2}{*}{ Total } \\
\hline & & Right-handed & Left-handed & \\
\hline \multirow{2}{*}{ Male } & $\mathrm{n}$ & 54 & 13 & 67 \\
\hline & $\%$ & 75.93 & 24.07 & 100,00 \\
\hline \multirow{2}{*}{ Female } & $\mathrm{n}$ & 56 & 11 & 67 \\
\hline & $\%$ & 80.36 & 19.64 & 100,00 \\
\hline \multirow[b]{2}{*}{ Total } & $\mathrm{n}$ & 110 & 24 & 134 \\
\hline & $\%$ & 82,08 & 17,92 & 100,00 \\
\hline
\end{tabular}

Regardless of hand preference, there is a weak positive correlation between right hand 2D:4D and left hand 2D:4D (r $=, 246 ; \mathrm{p}=, 045)$ in males, and between right/left hand and 2D:4D $(\mathrm{r}=, 228 ; \mathrm{p}=, 034)$ in females (Table 4.)

Table 4. Right hand 2D:4D ratio and the relation of left hand 2D:4D ratio

\begin{tabular}{llllll}
\hline & $\mathrm{n}$ & & & Left hand 2D:4D \\
Male & 67 & Right hand 2D:4D & $\mathrm{r}$ &, $246^{*}$ \\
& & & $\mathrm{p}$ & 0.045 \\
& & $\mathrm{r}$ &, $228^{*}$ \\
Female & 67 & Right hand 2D:4D & & \\
& & & $\mathrm{p}$ & 0.034 \\
\hline
\end{tabular}

When the hand preferences and 2D:4D ratios were compared in all the athletes, a statistically meaningful difference was detected $(\mathrm{p}<0.05)$ and a strong positive correlation was identified in all the comparisons as well (Table 5.).

Table 5. 2D:4D comparison based on the athletes' hand preferences

\begin{tabular}{|c|c|c|c|c|c|}
\hline & $\mathrm{n}$ & Hand preference & & & Left hand 2D:4D \\
\hline \multirow{4}{*}{ Male } & \multirow{2}{*}{54} & \multirow{2}{*}{ Right-handed } & \multirow{2}{*}{ Right hand 2D:4D } & $\mathrm{r}$ & $0.844 * *$ \\
\hline & & & & $\mathrm{p}$ & 0.01 \\
\hline & \multirow{2}{*}{13} & \multirow{2}{*}{ Left-handed } & \multirow{2}{*}{ Right hand 2D:4D } & $\mathrm{r}$ & $0.767 * *$ \\
\hline & & & & $\bar{p}$ & 0.01 \\
\hline \multirow{4}{*}{ Female } & \multirow{2}{*}{56} & \multirow{2}{*}{ Right-handed } & \multirow{2}{*}{ Right hand 2D:4D } & $\mathrm{r}$ & $0.867 * *$ \\
\hline & & & & $\mathrm{p}$ & 0.01 \\
\hline & \multirow{2}{*}{11} & \multirow{2}{*}{ Left-handed } & \multirow{2}{*}{ Right hand 2D:4D } & $\mathrm{r}$ & $0.851 * *$ \\
\hline & & & & $p$ & 0.01 \\
\hline
\end{tabular}

$\mathrm{p}<0.05$

It was found that the 2D:4D ratios of the male athletes are significantly lower than that of the female athletes (p<0,05), (Table 6.). 
Table 6. Comparison of hand preference and 2D:4D based on gender

\begin{tabular}{|c|c|c|c|c|c|c|c|}
\hline & & Gender & $\mathbf{N}$ & Ave. & SD & $t$ & $\mathbf{p}$ \\
\hline \multirow{4}{*}{ Right-handed } & \multirow{2}{*}{ Right hand } & Male & 54 & 0,93 & 0,01 & \multirow{2}{*}{$-6,596$} & \multirow{2}{*}{$0.000 *$} \\
\hline & & Female & 56 & 0,95 & 0,02 & & \\
\hline & \multirow{2}{*}{ Left hand } & Male & 54 & 0,96 & 0,02 & \multirow{2}{*}{$-5,243$} & \multirow{2}{*}{$0.000 *$} \\
\hline & & Female & 56 & 0,98 & 0,02 & & \\
\hline \multirow{4}{*}{ Left-handed } & \multirow{2}{*}{ Right hand } & Male & 13 & 0,97 & 0,01 & \multirow{2}{*}{6,633} & \multirow{2}{*}{$0.000 *$} \\
\hline & & Female & 11 & 0,98 & 0,01 & & \\
\hline & \multirow{2}{*}{ Left hand } & Male & 13 & 0,93 & 0,05 & \multirow{2}{*}{$-3,167$} & \multirow{2}{*}{$0.005 *$} \\
\hline & & Female & 11 & 0,95 & 0,01 & & \\
\hline
\end{tabular}

$\mathrm{p}<0.05$

In all the groupings, it was detected that the values of DH and 2D:4D are lower than those of NDH and 2D:4D (Table 7.).

Table 7. Comparison of DH and NDH with 2D:4D

\begin{tabular}{|c|c|c|c|c|c|c|c|}
\hline & Hand preference & & $\mathbf{N}$ & Average & Std. Deviation & $\mathbf{t}$ & $\mathbf{p}$ \\
\hline \multirow{3}{*}{ Male } & Right-handed & $\begin{array}{l}\text { DH 2D:4D } \\
\text { NDH 2D:4D }\end{array}$ & $\begin{array}{l}54 \\
13\end{array}$ & $\begin{array}{l}0,93 \\
0,961\end{array}$ & $\begin{array}{l}0,021 \\
0,018\end{array}$ & $-13,047$ & $0,000 *$ \\
\hline & \multirow{2}{*}{ Left-handed } & NDH 2D:4D & 54 & 0,975 & 0,02 & \multirow{2}{*}{9,135} & \multirow{2}{*}{$0.000 *$} \\
\hline & & DH 2D:4D & 13 & 0,933 & 0,029 & & \\
\hline \multirow{2}{*}{ Female } & Right-handed & $\begin{array}{l}\text { DH 2D:4D } \\
\text { NDH 2D:4D }\end{array}$ & $\begin{array}{l}56 \\
11\end{array}$ & $\begin{array}{l}0,95 \\
0,98\end{array}$ & $\begin{array}{l}0,019 \\
0,02\end{array}$ & $-10,212$ & $0.000^{*}$ \\
\hline & Left-handed & $\begin{array}{l}\text { NDH 2D:4D } \\
\text { DH 2D:4D }\end{array}$ & $\begin{array}{l}56 \\
11\end{array}$ & $\begin{array}{l}0,98 \\
0,947\end{array}$ & $\begin{array}{l}0,019 \\
0,018\end{array}$ & 7216 & $0.000^{*}$ \\
\hline
\end{tabular}

$\mathrm{p}<0.05 \mathrm{DH}$ : dominant hand - NDH: non-dominant hand

In the right-handed males, a moderate negative correlation between right hand 2D:4D and DHGS $(r=-, 537 ; \mathrm{p}=0)$ was detected. However, while there is a moderate negative correlation between left hand 2D:4D and DHGS $(r=-, 528 ; p=0)$, a weak negative correlation between left hand 2D:4D and NDHGS $(\mathrm{r}=-, 355 ; \mathrm{p}=0.008)$ was determined in the right-handed males. On the other hand, in the left-handed males, a moderate negative correlation between left hand 2D:4D and DHGS $(\mathrm{r}=, 470 ; \mathrm{p}=0.004)$ and a weak negative correlation between left hand 2D:4D and NDHGS ( $\mathrm{r}=-, 347 ; \mathrm{p}=0.007)$ was found. There is not a meaningful correlation between right hand 2D:4D and DHGS/ NDHGS in the left-handed males.

As for the right-handed females, there is a moderate negative correlation between right hand 2D:4D and DHGS $(\mathrm{r}=, 532 ; \mathrm{p}=0)$, right hand 2D:4D and NDHGS $(\mathrm{r}=, 506 ; \mathrm{p}=0)$, left hand 2D:4D and DHGS $(\mathrm{r}=-, 481 ; \mathrm{p}=0)$, and left hand 2D:4D and NDHGS ( $r=-, 483 ; p=0)$.

In the left-handed females; on the other hand, while there is a moderate negative correlation between right hand 2D:4D and DHGS ( $\mathrm{r}=-, 581 ; \mathrm{p}=0.007)$, there is not a meaningful correlation between the same variable and NDHGS. However, a moderate negative correlation between left hand 2D:4D and DHGS ( $\mathrm{r}=-, 589 ; \mathrm{p}=0.006)$ and left hand 2D:4D and NDHGS $(\mathrm{r}=-, 534 ; \mathrm{p}=0.015)$ was detected (Table 8.).

Table 8. Correlation between 2D:4D and hand grip strength

\begin{tabular}{|c|c|c|c|c|c|}
\hline \multirow{9}{*}{ Male } & & \multirow{3}{*}{ Right hand 2D:4D } & & DHGS & NDHGS \\
\hline & \multirow{4}{*}{ Right-handed } & & $\mathrm{r}$ &,$- 537^{* *}$ &,- 245 \\
\hline & & & $\mathrm{p}$ & 0 & 0.074 \\
\hline & & \multirow{2}{*}{ Left hand 2D:4D } & $\mathrm{r}$ &,$- 528^{* *}$ &,$- 355^{* *}$ \\
\hline & & & $\mathrm{p}$ & 0 & 0.008 \\
\hline & \multirow{4}{*}{ Left-handed } & \multirow{2}{*}{ Right hand 2D:4D } & $\mathrm{r}$ &,- 269 &,- 257 \\
\hline & & & $\mathrm{p}$ & .118 & .136 \\
\hline & & \multirow{2}{*}{ Left hand 2D:4D } & $\mathrm{r}$ &,$- 470^{* *}$ &,$- 347^{* *}$ \\
\hline & & & $\mathrm{p}$ & .004 & .007 \\
\hline \multirow{8}{*}{ Female } & \multirow{4}{*}{ Right-handed } & \multirow{2}{*}{ Right hand 2D:4D } & $\mathrm{r}$ &,$- 532^{* *}$ &,$- 506^{* *}$ \\
\hline & & & $\mathrm{p}$ & 0 & 0 \\
\hline & & \multirow{2}{*}{ Left hand 2D:4D } & $r$ &,$- 481^{* *}$ &,$- 483^{* *}$ \\
\hline & & & $\mathrm{p}$ & 0 & 0 \\
\hline & \multirow{4}{*}{ Left-handed } & \multirow{2}{*}{ Right hand 2D:4D } & $\mathrm{r}$ &,$- 581^{* *}$ &,- 313 \\
\hline & & & $\mathrm{p}$ & 0.007 & 0.179 \\
\hline & & \multirow{2}{*}{ Left hand 2D:4D } & $\mathrm{r}$ &,$- 589^{* *}$ &,$- 534^{*}$ \\
\hline & & & $\mathrm{p}$ & 0.006 & 0.015 \\
\hline
\end{tabular}

p<0.05 DHGS: dominant hand grip strength- NDHGS: non-dominant hand grip strength 
There is not a meaningful correlation between the age and right/left hand 2D:4D and DHGS/ NDHGS, between the years in the sports and right/left hand 2D:4D, and between the BMI and right/left hand 2D:4D of the athletes. However, a weak positive correlation between the years in the sports and DHGS $(r=, 214 ; p=0.041)$, a very weak positive correlation between the years in the sports and NDHGS $(\mathrm{r}=187 ; \mathrm{p}=0.032)$ was found. There is a weak negative correlation between the height and right hand $2 \mathrm{D}: 4 \mathrm{D}(\mathrm{r}=, 228 ; \mathrm{p}=0.008)$, a moderate positive correlation between the same variable and DHGS $(\mathrm{r}=, 550 ; \mathrm{p}=0)$, and a moderate positive correlation with NDHGS $(\mathrm{r}=, 558 ; \mathrm{p}=0)$. Although there is a moderate positive correlation between the weight and DHGS ( $r=482 ; \mathrm{p}=0.002)$, there is a weak negative correlation between NDHGS and the same variable $(\mathrm{r}=-, 186 ; \mathrm{p}=0.051)$. Finally, while a weak negative correlation between the BMI and right hand 2D:4D ( $\mathrm{r}=257 ; \mathrm{p}=0.003)$ was detected, a strong positive correlation between DHGS and this variable was found $(r=, 648 ; p=0)$. However, there is a strong positive correlation between the BMI and NDHGS $(\mathrm{r}=, 665 ; \mathrm{p}=0)$.

Table 9. Correlation between 2D:4D and gripping strength of the athletes with regard to some of their features

\begin{tabular}{l|lllll}
\hline & & Right hand 2D:4D & Left hand 2D:4D & DHGS & NDHGS \\
\hline \multirow{2}{*}{ Age } & $\mathrm{r}$ & $-0,069$ & 0,124 & $-0,168$ & $-0,163$ \\
\cline { 2 - 6 } & $\mathrm{p}$ & 0.425 & 0.15 & 0.051 & 0.058 \\
\hline \multirow{2}{*}{ Years in the Sports } & $\mathrm{r}$ & $-0,07$ & 0,132 &, $214^{*}$ &, $187^{*}$ \\
\cline { 2 - 6 } & $\mathrm{p}$ & 0.416 & 0.127 & $\mathbf{0 . 0 4 1}$ & $\mathbf{0 . 0 3 2}$ \\
\hline \multirow{2}{*}{ Height } & $\mathrm{r}$ &,$- 228^{* *}$ & $-0,16$ &, $550^{* *}$ &, $558^{* *}$ \\
\cline { 2 - 6 } & $\mathrm{p}$ & 0.008 & 0.063 & $\mathbf{0}$ & $\mathbf{0}$ \\
\hline \multirow{2}{*}{ Weight } & $\mathrm{r}$ & 0.512 & 0,136 & $.482^{* *}$ & -0.186 \\
\cline { 2 - 6 } & $\mathrm{p}$ & 0.007 & 0.062 & $\mathbf{0 . 0 0 2}$ & 0.051 \\
\hline \multirow{2}{*}{ BMI } & $\mathrm{r}$ &,$- 257^{* *}$ & $-0,154$ &, $648^{* *}$ &, $665^{* *}$ \\
\cline { 2 - 6 } & $\mathrm{p}$ & 0.003 & 0.073 & $\mathbf{0}$ & $\mathbf{0}$ \\
\hline
\end{tabular}

$\mathrm{p}<0.05$ DHGS: dominant hand grip strength - NDHGS: non-dominant hand grip strength

\section{Discussion and Conclusions}

The correlation with hand preference, 2D:4D and hand grip strength in elite handball players was investigated in this study. As a result of the study, it was determined that while the ratio of right-handedness is $\% 75.93$, left-handedness is $\% 24.07$ in male athletes. As for the female athletes, although the ratio of right-handedness is $\% 80.36$, the ratio of left-handedness is \%19.64. The ratio of the right-handed dominancy in the population of Turkey ranges from \%85 to 90 . Whereas $\% 90.8$ of the male population is right-handed, only $\% 6.1$ of them is left-handed. However, $\% 3.1$ of males uses both of their hands. On the other hand, the ratio of right-handedness is $\% 92.3$ and that of left-handedness is $\% 4.4$ in females. The $\% 3.3$ of the female population in Turkey uses their both hands. Left-handedness was determined to be $\%$ 1-2 higher in males than it is in females (Kütükçüoğlu, 1993). Loffing et al. (2012a) found the rate of left-handedness as \%11.11 among the volleyball players participating in their study $(\mathrm{n}=36)$. They suggested that $\% 34.4$ of the male tennis players who were at the top of the world rank from 1968 to 1999 was left-handed. Besides, they also reported that just $\% 7$ of the whole players who were in the list was left-handed. Similar results for baseball and cricket were also presented in the same study. Left-handedness could provide some advantages for athletes in many different sports. This situation might be associated with the higher ratio of athletes' left hand preference when compared to the normal population. Moreover, it is thought that the number of left-handed players in handball teams is higher due to the game system and position.

Regardless of hand preference, when the ratio of the right hand 2D:4D and left hand 2D:4D was compared, there is a weak positive correlation in the males $(r=, 246 ; p=0.045)$ and in the females $(r=, 228 ; p=0.034)$. A meaningful strong positive correlation was found between the hand preference and $2 \mathrm{D}: 4 \mathrm{D}$ both in the male and female athletes. There is a meaningful difference between the mean right and left hand 2D:4D values of the right and left-handed athletes [In the right-handed males, right hand 2D:4D 0.930 \pm 0.02- left hand $0.960 \pm 0.018$; in the left-handed males, right hand 0.975 \pm 0.02 - left hand $0.933 \pm 0.02$ ]. In the right-handed females, right hand $0.950 \pm 0.01$ - left hand $0.98 \pm 0.02$; in the left-handed females, right hand $0.980 \pm 0.01$ - left hand $0.94 \pm 0.01$ ]. While Kilduff et al. (2011) determined the right hand 2D:4D ratios of male surfers as 0.944 in their study, they found the left hand 2D:4D ratios of them as 0.976 . Bennett et al. (2010) detected the right hand 2D:4D ratios of male rugby players as 0.963 and those of the left hand as 0.956 . The right and left hand 2D:4D ratios of the male players in our study present similar results with these studies. When the ratios of DH 2D:4D were compared with NDH 2D:4D in both the right-handed and left-handed players, the first one was found to be statistically lower than the latter one in a meaningful way ( $\mathrm{p}<0.05)$. Manning (2002) and Lutchmaya et al. (2004) found that the 2D:4D ratios of the both hands of the males were lower than those of the females. The results of the studies are similar and they support the findings in the literature regarding the fact that the negative 
correlation between 2D:4D ratios and prenatal testosterone is higher in males than females (Manning et al., 1998; Hönekopp and Schuster, 2010; Gökbel et al., 1992).

In our study, the DHGS of the right-handed male athletes is $53,96 \pm 5,17 \mathrm{~kg}$, the NDHGS is $49,7 \pm 4,92 \mathrm{~kg}$; the same variables for the left-handed male athletes are $51.08 \pm 5,2 \mathrm{~kg}$ and $47.92 \pm 5,31 \mathrm{~kg}$, respectively. On the other hand, the DHGS of the right-handed female athletes is $40.86 \pm 4.94 \mathrm{~kg}$ and $37.31 \pm 4,76 \mathrm{~kg}$ for the NDHGS; those of the left-handed female athletes are $40.45 \pm 4.51 \mathrm{~kg}$ and $36.35 \pm 4.2 \mathrm{~kg}$, respectively. The values of the DHGS were detected to be higher than those of the NDHGS in both the male and female athletes. In their study carried out on the athletes who were between 18-25 years old $(n=103)$, Koley and Singh (2010) found the DHGS and NDHGS in the right-handed male athletes as $41.31 \pm 6.00 \mathrm{~kg}$ and $38.14 \pm 6.20 \mathrm{~kg}$, respectively; those of the left-handed male athletes $(\mathrm{n}=48)$ as $41.12 \pm 6.88 \mathrm{~kg}$ ve $37.76 \pm 7.34 \mathrm{~kg}$, respectively . They; on the other hand, found the DHGS and NDHGS in the right-handed female athletes $(\mathrm{n}=129)$ as $23.82 \pm 3.71 \mathrm{~kg}$ and $21.03 \pm 3.49 \mathrm{~kg}$, respectively. As for the left-handed female athletes $(\mathrm{n}=23)$, they determined the values of the same variables as $23.48 \pm 3.29 \mathrm{~kg}$ and $21.46 \pm 3.37 \mathrm{~kg}$, respectively. They found a significant difference in favor of the dominant hand in both gender. In their study carried out on males and females ( $\mathrm{n}=303)$ who were between 23-29 years old, Fuster et al. (1998) found the right hand grip strength as $50.21 \pm 7.1 \mathrm{~kg}$ and that of the left hand as $46.90 \pm 7.8 \mathrm{~kg}$ in the males; the right hand grip strength as $30.06 \pm 4.1 \mathrm{~kg}$ and that of the left hand as $27.82 \pm 4.7 \mathrm{~kg}$ in the females.

Atabek (2014) detected the average DHGS of female handball players whose age mean was $19 \pm 2.18$ as $32.22 \pm 3.93 \mathrm{~kg}$ and Koley et., al. (2011) found the average right/left hand grip strength of female handball players $(\mathrm{n}=101)$ whose age mean was $20.52 \pm 1.40$ as $30.01 \pm 3.86 \mathrm{~kg}$ and $26.80 \pm 3.69 \mathrm{~kg}$.

There are similarities between the results of the studies; however, the average of the gripping strength in our study can be said to be higher than the averages of the other studies.

These differences are thought to be originated not only from the variables such as age and the branch of the sports but also from the fact that all the athletes in our study are professional elite handball players. This situation reveals the importance of gripping strength in handball in which hand, forearm strength and hand strength skills are crucial. Moreover, it supports our thoughts underlying the importance of determining gripping strength in handball.

A high negative correlation between male and female 2D:4D and DHGS and NDHGS was found in this study. Fink et al. (2006) identified a very weak but meaningful correlation between hand grip strength and right hand 2D:4D in both Indian and German participants (India, $\eta^{2}=0.046$; Germany, $\eta^{2}=0.073$ ). In the study that was carried out on 46 surfers, Kilduff et al. (2007) determined a strong negative correlation between 2D:4D and surf performance ( $\mathrm{rs}=0.51, \mathrm{r}^{2}=0.26$, p, 0.0001). Tester and Campbell (2007) detected a significant negative correlation between 2D:4D and performance in a universe consisting of male basketball, rugby and football players.

Manning and Taylor (2001) found a significant negative correlation between the sports ranking of the athletes, footballers, martial artists, rugby, tennis, squash and hockey players $(b=222.73, F=10.99, p=0.01)$, even regardless of their age, sports age and branch (each athlete identified his or her own rank from 1 to 10 , and 10 represents international participation). In another research consisting of 52 male and 20 female skiers, a direct correlation was determined between the control group and 2D:4D when investigated in terms of age, gender and ethnicity; besides, it was also found that the control group had higher 2D:4D when compared with the skiers (Manning, 2002). There is a negative correlation regarding females between 2D:4D and sports talent in individual sports (Malas et al., 2006; Pokrywka et al., 2005).

In this study, a meaningful difference was not found between the age and right/left hand 2D:4D and dominant/non-dominant hand grip strength values of the athletes $(\mathrm{p}>0.05)$. Although there is a positive correlation between sport age and DHGS/NDHGS, height and DHGS/NDHGS, weight and DHGS/NDHGS, and BMI and DHGS/NDHGS, there is a meaningful negative correlation between height and right hand 2D:4D, and BMI and right hand 2D:4D. Fink et al. (2006) determined significant differences between age, weight, height and 2D:4D; and between the same variables and hand grip strength (India $=0.073$; Germany $=0.077$ ).

A meaningful difference between age and DHGS/NDHGS was not detected in our study (p>0.05). Gerodimos (2012) found an increase in gripping strength as the age increases in his study in which he involved three groups of basketball players $(\mathrm{n}=90)$ belonging to different ages $(\mathrm{p}<0.05)$ Bansode et al. (2014) found out a significant positive correlation between DHGS and age in a study consisting of 121 healthy individuals. The results of our study are different than these results. Similar results in our study were found when the years in the sports and DHGS/NDHGS were compared. Gümüş and Akalın (2016) suggested that there is not a significant correlation between the experience in the sports and gripping strength (DHGS, $\mathrm{r}=0.035, \mathrm{p}=0.791$ ), (NDHGS, $\mathrm{r}=0.039, \mathrm{p}=0.764)$. Zorba et al., (2014) state that there is not a statistically meaningful difference between the years in the sports and left/right hand grip strength in elite handball players $(n=23)$ whose age mean is $23.96 \pm 2.79$ and who has an $8.30 \pm 1.74$ mean of the years in the sports $(\mathrm{p}<0.05)$. 
These results present a difference from our findings. In order to explain the correlation between gripping strength and experience in sports more clearly in handball, it can be said that new studies are needed that have groups of new beginners and elite athletes in which different age groups can be compared.

This study has important results in handball: a- the rate of left-handed athletes is more than that of the left-handed people in the general population b- there is a strong correlation between $2 \mathrm{D}: 4 \mathrm{D}$ and hand preference c- there is a negative strong correlation between 2D:4D and left/right hand grip strength $\mathrm{d}$ - male athletes have lower 2D:4D than female athletes e- a meaningful correlation between height / BMI and 2D:4D, years in the sports/ height/ weight and gripping strength was found. Last but not least, we can say that $2 \mathrm{D}: 4 \mathrm{D}$, right-handedness, left-handedness and the importance of gripping strength are emphasized in this study.

\section{References}

Abel, E., \& Kruger, M. (2004). Relation of handedness with season of birth of Professional baseball players revisited. Perceptual and Motor Skills, 98, 44-46. https://doi.org/10.2466/pms.98.1.44-46

Atabek, H. Ç. (2014). The relationship between hand-grip strength, anaerobic performance and isokinetic muscle strength in female handball players. Niğde University Journal of Physical Education And Sport Sciences, 8(3), 242-250.

Baker, J, Kungl, A. M., Pabst, J., Straub, B., Büsch, D., \& Schorer, J. (2013). Your fate is in your hands? Handedness, digit ratio (2D:4D), and selection to a national talent development system. Laterality: Asymmetries of Body,Brain and Cognition, 18, 710-718. https://doi.org/10.1080/1357650X.2012.755992

Bansode, D. G., Borse, L. J., \& Yadav, R. D. (2014). Study of correlation between dominant hand's grip strength and some physical factors in adult males and females, International Journal of Pharma Research and Health Sciences, 2(4), 316-323.

Bennett, M., Manning, J. T., Cook, C. J., \& Kilduff, L. P. (2010). Digit ratio (2d:4d) and performance in elite rugby players. Journal of Sports Sciences, 28, 1415-1421. https://doi.org/10.1080/02640414.2010.510143

Bryden, E. (1975). The other side of the brain VII. some educational aspects of hemispheric specialization, UCLA, 17, 24-32.

Çelik, A., Aksu, F., Tunar, M., Daşdan, A. E. N., \& Topaçoğlu, H. (2010). Master atletlerin fiziksel performans düzeylerinin eldeki parmak oranlarıyla ilişkisi. Deü Tıp Fakültesi Dergisi, 24 (1), 5-10.

Curt, F., Maccario, J., \& Dellatolas, G. (1992). Distributions of hand preference and hand skill asymmetry in preschool children: theoretical implications, Neuropsychologia, 30(1), 27-34. https://doi.org/10.1016/0028-3932(92)90011-A

Fink, B., Thanzami, V., Seydel, H., \& Manning, J. T. (2006). Digit ratio and hand-grip strength in German and Mizos men: Cross-cultural evidence for an organizing effect of prenatal testosterone on strength. American Journal of Human Biology, 18(6), 776-782. https://doi.org/10.1002/ajhb.20549

Fuster, V., Jerez, A., \& Ortega, A. (1998). Anthropometry and strength relationship: male-female differences. Anthropol Anz. 56(1), 49-56.

Galis, F., Ten, Broek, C. M. A., \& Van Dongen, S. (2010). Sexual dimorphism in the prenatal digit ratio (2D:4D). Archives of Sexual Behavior, 39(1), 57-62. https://doi.org/10.1007/s10508-009-9485-7

Gerodimos, V. (2012). Reliability of Handgrip Strength Test in Basketball Players, Journal of Human Kinetics, 31, 25-36. https://doi.org/10.2478/v10078-012-0003-y

Gökbel, H., Çalışkan, H., \& Kavun (Dölek), Ç. (1992). Genç erişkinlerde el tercihi ile testosteron seviyeleri arasındaki ilişki. 35.SU Tip Fakültesi Dergisi, 8, 207-209.

Gümüş, M., \& Akalın, T. C. (2016). The hand preference of the national sportsmen and evaluation of the grasp forces. International Journal of Academic Research, 8(6), 45-50. https://doi.org/10.7813/2075-4124.2016/8-6/A.5

Harris, L. J. (2010). In fencing, what gives left-handers the edge? Views from the present and the distant past. Laterality, 15(1), 15-55. https://doi.org/10.1080/13576500701650430

Hönekopp, J., \& Schuster, M. (2010). A meta-analysis on 2D:4D and athletic prowess: Substantial relationships but neither hand out-predicts the other. Personality and Individual Differences, 48, 4-10. https://doi.org/10.1016/j.paid.2009.08.009

Hönekopp, J., \& Watson, S. (2011). Meta-analysis of the relationship between digit-ratio 2d:4d and aggression. Personality and Individual Differences, 51, 381-386. https://doi.org/10.1016/j.paid.2010.05.003 
Hönekopp, J., Manning, J. T, \& Muller, C. (2006). Digit ratio (2D:4D) and physical fitness in males and females: Evidence for effects of prenatal androgens on sexually selected traits. Hormones and Behavior, 49, 545-549. https://doi.org/10.1016/j.yhbeh.2005.11.006

Jürimäe, T., Voracek, M., Jürimäe, J., Lätt, E., Haljaste, K., Saar, M., \& Purge, P. (2008). Relationships between Wnger-length ratios, ghrelin, leptin, IGF axis, and sex steroids in young male and female swimmers. European Journal of Applied Physiology, 104, 523-529. https://doi.org/10.1007/s00421-008-0801-z

Kaplan, Ö. D. (2016). Evaluating the relation between dominant and non-dominant hand perimeters and handgrip strength of basketball, volleyball, badminton and handball athletes, International Journal of Environmental and Science Education, 11(10), 3297-3309

Kaur, M. (2009). Age-related changes in hand grip strength among rural and urban Haryanvi Jat females. J. Copmar. Journal of Comparative Human Biology, 60, 441-450. https://doi.org/10.1016/j.jchb.2009.06.002

Kılduff, L. P., Cook, C. J. \& Mannıng, J. T. (2011). Digit ratio (2d:4d) and performance in male surfers. Journal Of Strength And Conditioning Research. 25(11), 3175-3180. https://doi.org/10.1519/JSC.0b013e318212de8e

Koley, S., \& Singh, A. P. (2010). Effect of hand dominance in grip strength in collegiate population of Amritsar, Punjab, India. Anthropologist, 12(1), 13-16. https://doi.org/10.1080/09720073.2010.11891125

Koley, S., Kaur, N., \& Sandhu, J. S. (2009). Association of hand grip strength and some anthropometric traits in female labourers of Jalandhar, Punjab, India. Journal of Life Science, 1, 57-62. https://doi.org/10.1080/09751270.2009.11885135

Koley, S., Kaur, S. P, \& Sandhu, J. P. (2011). Correlations of handgrip strength and some anthropometric variables in Indian inter- university female handball players. Sport Science Review, 20(3-4), 57-68. https://doi.org/10.2478/v10237-011-0054-3

Kütükçüoğlu, Y. (1993). El baskınlığının yönü ve derecesinin araştırılması. Ankara: GATA Nöroloji Anabilim Dalı, Uzmanlık Tezi.

Lawler, T. P., \& Lawler, F. H. (2011). Left-handedness in professional basketball: prevalence, performance, and surviva. Perceptual and Motor Skills, 11(3), 815-824. https://doi.org/10.2466/05.19.25.PMS.113.6.815-824

Loffing, F., Hagemann, N., \& Strauss, B. (2010). Automated processes in tennis: Do left-handed players benefit from the tactical preferences of their opponents? Journal of Sports Sciences, 28, 435-443. https://doi.org/10.1080/02640410903536459

Loffing, F., Schorer, J., Hagemann, N., \& Baker, J. (2012a). On the advantage of being left-handed in volleyball: further evidence of the specificity of skilled visual perception. Attention, Perception\&Psychophysics, 74, 446. https://doi.org/10.3758/s13414-011-0252-1

Loffing, F., Schorer, J., Hagemann, N., \& Baker, J. (2012b). Human handedness in interactive situations: Negative perceptual frequency effects can be reversed! Journal of Sports Sciences, 30, 507-513. https://doi.org/10.1080/02640414.2012.654811

Lutchmaya, S., Baron-Cohen, S., \& Raggatt, P. (2004). 2nd and 4th digit ratio, fetal testosterone and estradiol. Early Hum Dev., 77(1-2), 23-28. https://doi.org/10.1016/j.earlhumdev.2003.12.002

Malas, M. A., Dogan, S., Evcil, E. H., \& Desdicioglu, K. (2006). Fetal development of the hands, digits and digit ratio (2D:4D). Early Human Development, 82, 469-475. https://doi.org/10.1016/j.earlhumdev.2005.12.002

Manning, J. T. (2002). The ratio of 2nd to 4th digit length and performance in skiing. Journal of Sports Medicine Physical Fitness, 42, 446-450.

Manning, J. T., \& Taylor, R. P. (2001). Second To fourth digit ratio and male ability in sport: implications for sexual selection in humans. Evolution And Human Behavior, 22, 61-69. https://doi.org/10.1016/S1090-5138(00)00063-5

Manning, J. T., Scutt, D., Wilson, J., \& Lewis-Jones, D. I. (1998). The ratio of 2nd to 4th digit length: A predictor of sperm numbers and levels of testosterone, LH and oestrogen. Human Reproduction, 13, 3000-3004. https://doi.org/10.1093/humrep/13.11.3000

Moffit, D. M., \& Swanik, C. B. (2010). The association between athleticism, prenatal testosterone and finger length. Journal of Strength and Conditioning. Research., 20,55-9. https://doi.org/10.1519/JSC.0b013e3181d4d409

Phelps, V. R. (1952). Relative index finger length as a sex influenced trait in man. American Society of Human Genetics, 4, 472-89. 
Pokrywka, L., Rachon, D., \& Suchecka-Rachon, K. (2005). The second to fourth digit ratio in elite and non-elite female athletes. American Journal of Human Biology, 17(6), 796-800. https://doi.org/10.1002/ajhb.20449

Powel, J. L., Parkes, L., \& Kemp, G. J. (2012). The effect of sex and handedness on white matter anisotropy: a diffusion tensor magnetic resonance imaging study. Neuroscience, 207, 227-242. https://doi.org/10.1016/j.neuroscience.2012.01.016

Puterman, J., Schorer, J., \& Baker, J. (2010). Laterality differences in elite ice hockey: An investigation of shooting and catching orientations. Journal of Sports Sciences, 28, 1581-1593. https://doi.org/10.1080/02640414.2010.514281

Singh, A. P., Koley, S., \& Sandhu, J. S. (2009). Association of hand grip strength with some anthropometric traits in collegiate population of Amritsar. Orient. Anthropologischer Anzeiger, 9, 99-110.

Tamiya, R., Lee, S. Y., \& Ohtake, F. (2012). Second To Fourth Digit Ratio And The Sporting Success Of Sumo Wrestlers. Evolution and Human Behavior, 33, 130-136. https://doi.org/10.1016/j.evolhumbehav.2011.07.003

Tan, U. (1985). Left-right differences in the Hoffmann reflex recovery curve assciated with handednee in normal subjects. International Journal of Psychophysiology, 3, 75-78. https://doi.org/10.1016/0167-8760(85)90022-4

Tester, N., \& Campbell, A. (2007). Sporting achievement: What is the contribution of digit ratio? Journal of Personality, 75(4), 663-677. https://doi.org/10.1111/j.1467-6494.2007.00452.x

Van Honka, J., Schutter, D. J., Bos, P. A., Kruijt, A. W., Lentje,s E. G., \& Baron-Cohen, S. (2011). Testosterone administration impairs cognitive empathy in women depending on second-to-fourth digit ratio. Proceedings of The National Academy of Sciences Of The United States Of America, 108, 3448-3452. https://doi.org/10.1073/pnas.1011891108

Visnapuu, M., \& Jurımae, T. (2007). Handgrıp strength and hand dımensions in young handball and basketball players. Journal Of Strength And Conditioning Research, 21(3), 923-929.

Voracek, M., Reimer, B., \& Ertl, C. (2006). Digit ratio (2D:4D), lateral preferences, and performance in fencing. Perceptual and Motor Skills, 103, 427-446. https://doi.org/10.2466/pms.103.2.427-446

Zorba, E., Göral, K., \& Göral, Ş. (2014). Examining relationships between some physical fitness parameters of elite handball players. International Journal of Science Culture and Sport. Special issue 1, 68-76. https://doi.org/10.14486/IJSCS75

\section{Copyrights}

Copyright for this article is retained by the author(s), with first publication rights granted to the journal.

This is an open-access article distributed under the terms and conditions of the Creative Commons Attribution license which permits unrestricted use, distribution, and reproduction in any medium, provided the original work is properly cited. 